\title{
Human Comfort Evaluation of a Steel-Concrete Composite Building Subjected to Aerobics
}

\author{
José Guilherme S. da Silva ${ }^{1,2}$, Ana Cristina C. F. Sieira ${ }^{1,2}$, Fernanda F. Campista ${ }^{2}$ and Cássio M. R. Gaspar ${ }^{2}$ \\ 1. Structural Engineering Department (ESTR), State University of Rio de Janeiro (UERJ), Rio de Janeiro 20550-900, Brazil \\ 2. Civil Engineering Post-graduate Programme (PGECIV), State University of Rio de Janeiro (UERJ), Rio de Janeiro 20550-900, \\ Brazil
}

\begin{abstract}
The current steel-concrete composite floors design might be susceptible to the resonance phenomenon, causing undesirable vibrations in the frequency range that is the most noticeable to humans, i.e., $4 \mathrm{~Hz}$ to $8 \mathrm{~Hz}$. This way, the main objective of this work is to investigate the dynamic structural behaviour of a steel-concrete composite multi-storey building when subjected to human rhythmic activities (aerobics). The studied structural model represents a typical interior floor bay of a commercial building used for gym and is composed by three floor levels spanning $20 \mathrm{~m}$ by $20 \mathrm{~m}$, with a total area of $3 \times 400 \mathrm{~m}^{2}$. An extensive parametric study was developed aiming to obtain the peak accelerations, RMS (root mean square) accelerations and VDV (vibration dose value) values, based on two different mathematical formulations. The human comfort of the building was analysed and the vibration transmissibility related to the steel columns was verified. Based on the found results, the investigated structural model presented high vibration levels that compromise the human comfort.
\end{abstract}

Key words: Steel-concrete composite floors, structural dynamics, vibration analysis, human comfort, computational modelling.

\section{Introduction}

The current steel-concrete composite floors design might be susceptible to the resonance phenomenon causing undesirable vibrations in the frequency range that is the most noticeable to human perception, i.e., 4 $\mathrm{Hz}$ to $8 \mathrm{~Hz}$ [1-5]. On the other hand, at the same time, most of the natural frequencies of composite floor systems also lie in this range. In addition, the excitation force frequencies due to human rhythmic activities occur in this range as well. All these combinations make the structural systems more susceptible to the resonance phenomenon, causing undesirable vibrations and human discomfort [1-5].

Such condition is in part due to the technological advance in the materials field which has allowed the use of more resistant and low weight materials that result in slender and more flexible structural composite

Corresponding author: José Guilherme S. da Silva, professor, research fields: structural dynamics; vibration analysis; dynamic experimental monitoring; steel and steel-concrete structures; numerical modelling. floor systems. In addition, it has been observed in design practice low floor structural damping ratios, which is related to the type of construction, materials, presence of non-structural elements, age and also quality of the construction process $[1,2]$. Therefore, all these combinations make the steel-concrete composite floors very susceptible to annoying vibrations induced by human rhythmic activities.

In this sense, this investigation aims to evaluate the dynamic structural behaviour of a steel-concrete composite building, consisting of three floor levels spanning $20 \mathrm{~m}$ by $20 \mathrm{~m}$, with a total area of $3 \times 400 \mathrm{~m}^{2}$ used as gym for the practice of aerobics. This way, an extensive parametric analysis was developed aiming to obtain the peak accelerations, RMS accelerations and VDV values, based on two mathematical formulations used for modelling human rhythmic actions $[3,6,7]$.

Thus, along the present study, it was found that the analysed steel-concrete composite floor multi-storey building presented high vibration levels that compromise the human comfort, according to the 
limiting values proposed by several authors and design recommendations.

\section{Finite Element Modelling}

The finite element model was based on a steel-concrete composite floor spanning $20 \mathrm{~m}$ by $20 \mathrm{~m}$ with a total area of $3 \times 400 \mathrm{~m}^{2}$ composed by 12 bays of $10 \mathrm{~m}$ by $10 \mathrm{~m}$. The floor is made of composite beams and a $100 \mathrm{~mm}$ thick concrete slab. The columns height is equal to $4 \mathrm{~m}$ (Figs. 1 to 3 ). The steel sections used were WWF (welded wide flanges) made from a 345 MPa yield stress steel grade. A $205 \times 10^{3} \mathrm{MPa}$ Young's modulus was adopted for the steel beams. The concrete slab presents a $30 \mathrm{MPa}$ specified compression strength and a $26 \times 10^{3} \mathrm{MPa}$ Young's modulus [1].

The developed numerical model adopted the usual mesh refinement techniques present in finite element method simulations implemented in the ANSYS program [8]. The floor steel beams were represented by three-dimensional beam elements, where flexural and torsion effects are considered. The composite slab was represented by shell finite elements (Figs. 4 to 6).

The complete interaction between the concrete slab and steel beams was considered in the analysis, i.e., the numerical model coupled all the nodes between the beams and slab, to prevent the occurrence of any slip. Both materials (steel and concrete) present an elastic behaviour. Regarding the structural behaviour of the connections present in the investigated structural model, the beam-to-beam connections were modelled as flexible joints and the beam-to-column connections were considered as rigid joints [1].

\section{Human Rhythmic Activities Modelling}

The mathematical functions of the rhythmic dynamic loading is described in this work by two different experimental approaches such as proposed by Faisca [3], Ellis and Ji [6], and Smith, Hicks and Devine [7]. The dynamic loading Model I corresponds to the model proposed by Faisca [3] (Eq. (1)) and the dynamic loading Model II was developed by Ellis and
Ji [6], and Smith, Hicks and Devine [7] (Eqs. (2) to (5)). Figs. 7 and 8 show an example of the dynamic force for a single person in the time and frequency domain considering a frequency step of $2.17 \mathrm{~Hz}$. It is also assumed that a single person's weight is $800 \mathrm{~N}[1,2]$. Besides, it was considered a group of 50 people practising aerobics together in order to account the phase lag among them.

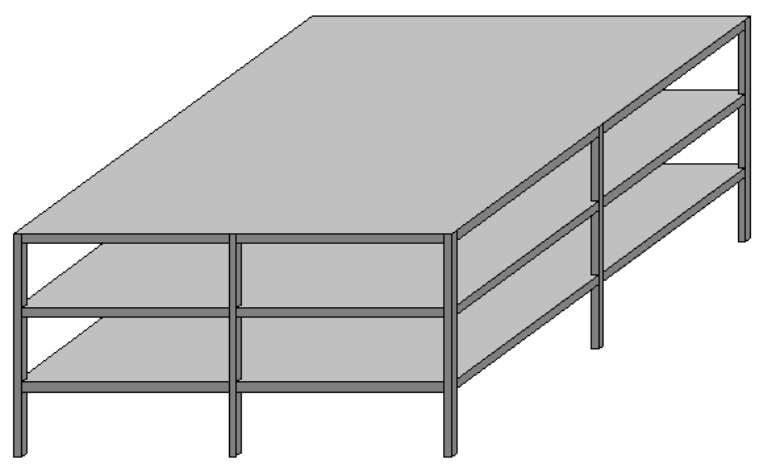

Fig. 1 Multi-storey building, three-dimensional model.

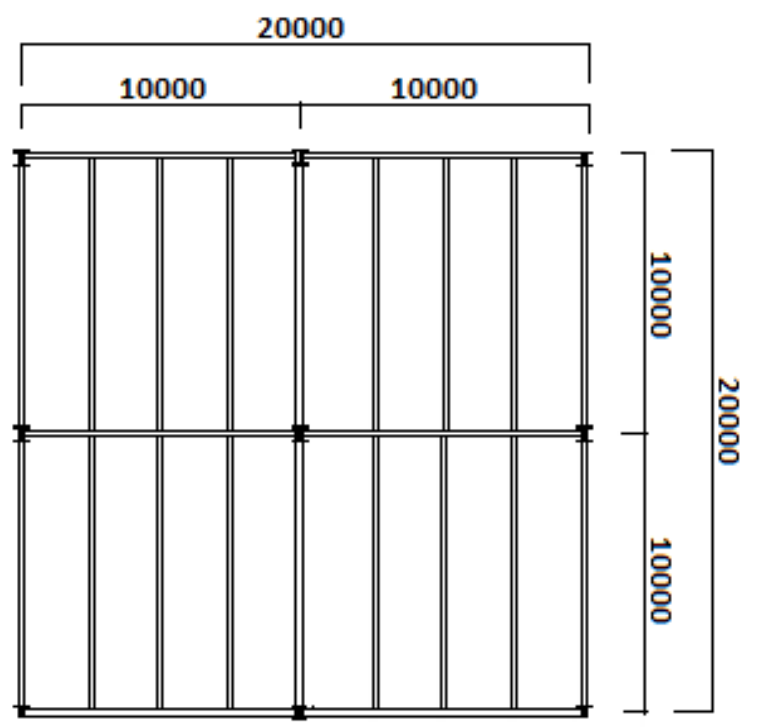

Fig. 2 Typical floor bay top view (units in $\mathbf{m m}$ ).

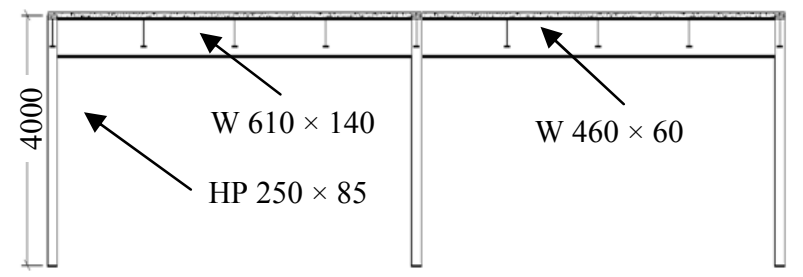

Fig. 3 Typical floor bay cross section (units in $\mathbf{m m}$ ). 


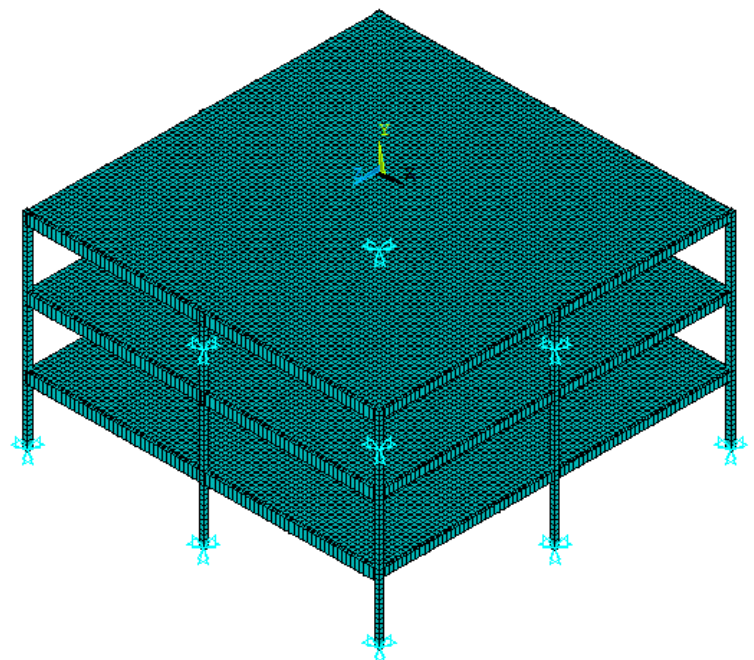

Fig. 4 Finite element model of the building.

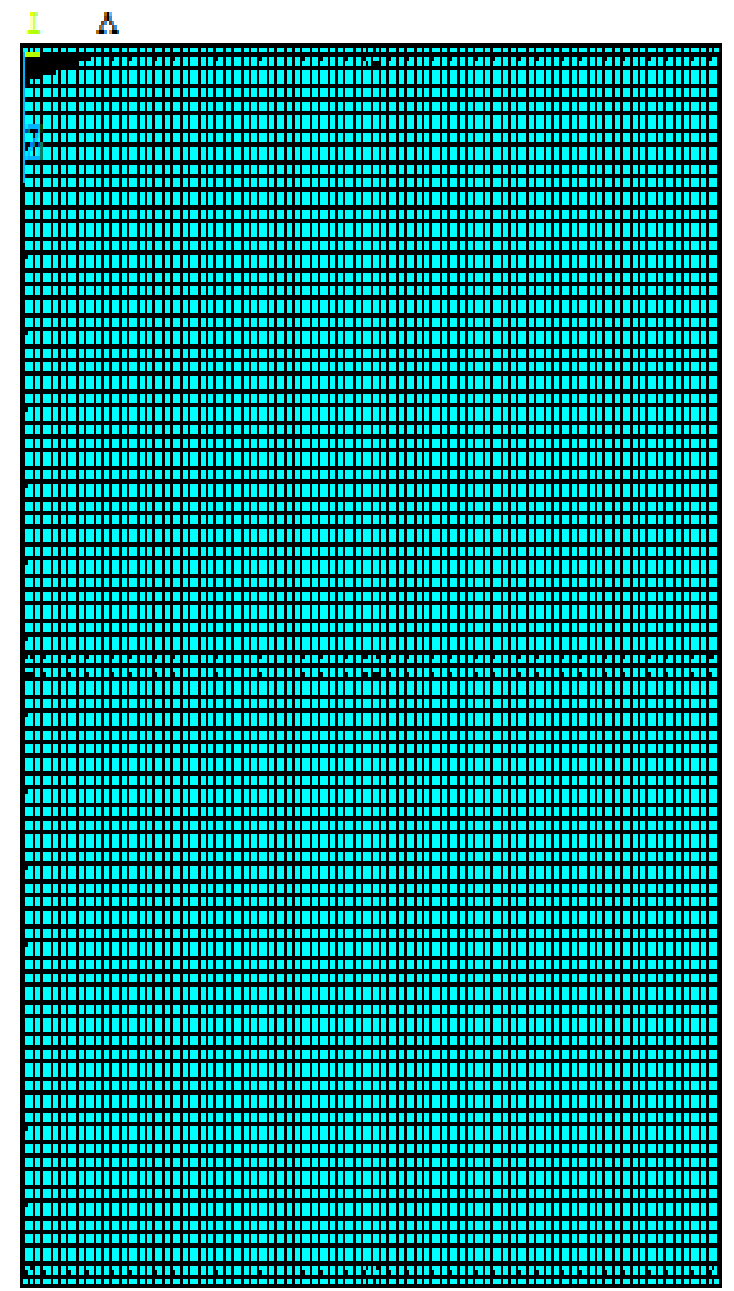

Fig. 5 Floor concrete slabs (top view).

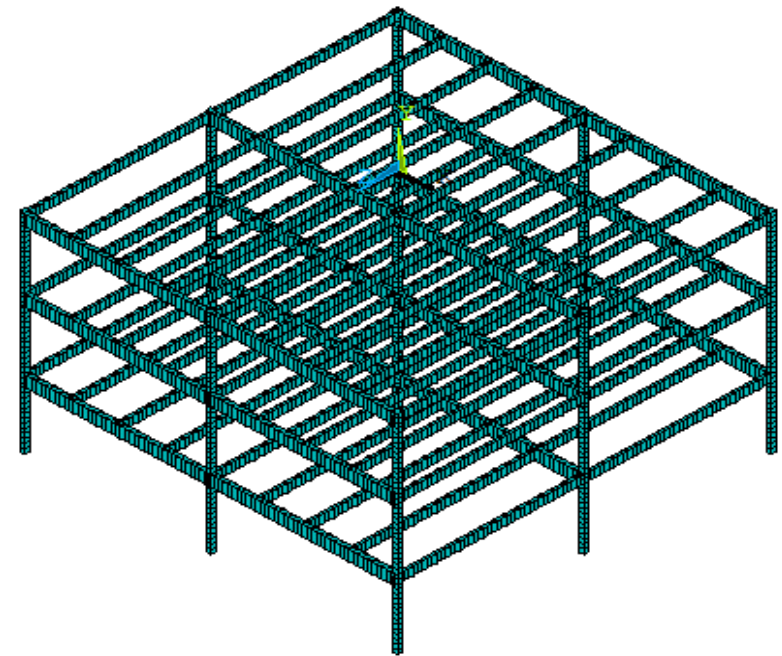

Fig. 6 Steel frame formed by columns and beams.

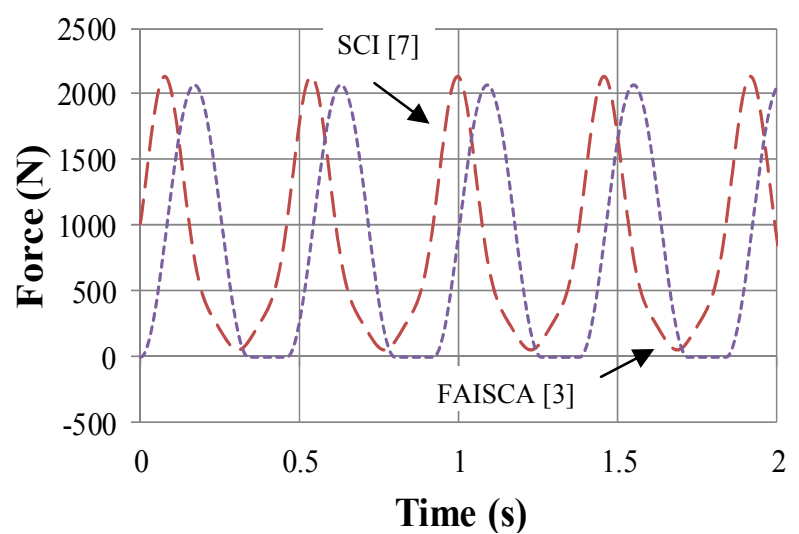

Fig. 7 Dynamic loading functions in time domain.

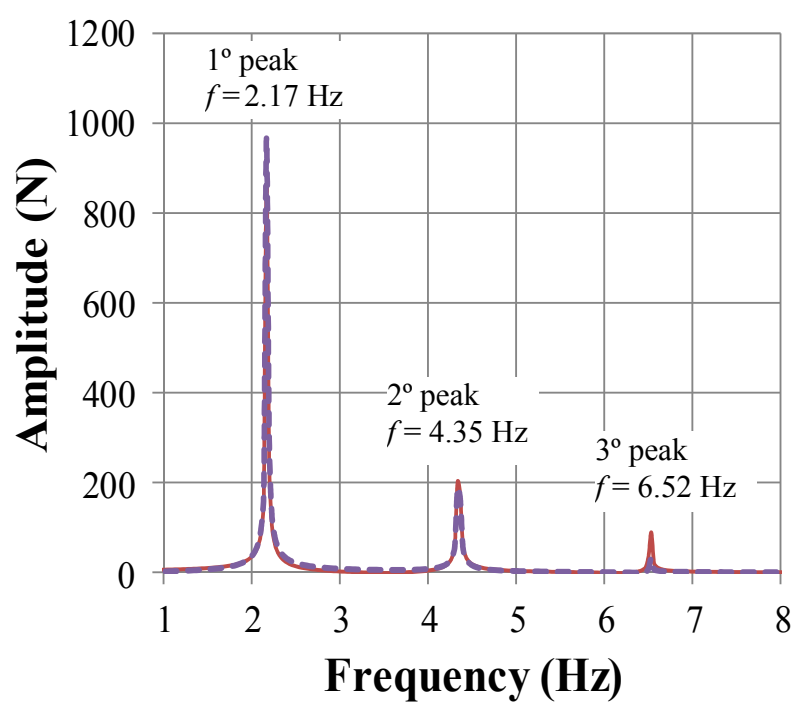

Fig. 8 Dynamic loading functions in frequency domain. 


$$
\begin{gathered}
F(t)=C D\left\{K_{p} P\left[0.5-0.5 \cos \left(\frac{2 \pi}{T_{c}} t\right)\right]\right\} \\
t \leq T_{c} \quad F(t)=0 \quad T_{c} \leq t \leq T
\end{gathered}
$$

where, $F(t)$ is the dynamic loading function $(\mathrm{N}), T$ represents the activity period (s); $T_{c}$ is the activity contact period (s); $P$ is the person's weight $(\mathrm{N}) ; K_{p}$ corresponds to the impact coefficient; $C D$ represents the phase coefficient and $t$ is the time (s).

$$
\begin{gathered}
F(t)=G\left\{1+\sum_{n=1}^{\infty} r_{n, v} \sin \left(2 n \pi f_{p} t+\phi_{n}\right)\right\} \\
r_{1, v}=1.61 v^{-0.082} \\
r_{2, v}=0.94 v^{-0.24} \\
r_{3, v}=0.44 v^{-0.31}
\end{gathered}
$$

where, $F(t)$ represents the dynamic loading function $(\mathrm{N}) ; f_{p}$ is the frequency of the jumping (excitation frequency) (Hz); $v$ : number of persons; $r_{n, v}:$ represents the Fourier coefficient of the $n$th term; $G$ is the person's weight $(\mathrm{N}) ; \phi_{n}$ is the phase lag of the $n$th term and $t$ is the time (s). The phase lag for the first three harmonics considering a crowd jumping is equal to $\pi / 6,-\pi / 6$ and $\pi / 2$, respectively.

\section{Natural Frequencies and Mode Shapes}

The modal analysis was performed and it was verified that the first 12 natural frequencies of the studied composite floor, varying from $6.29 \mathrm{~Hz}$ to 7.59 $\mathrm{Hz}$ (Table 1), are close to the excitation frequency range (aerobics). In this situation, the frequency of the third harmonic of the dynamic loading may match these natural frequencies and therefore lead the composite floor to a resonant motion. Therefore, such situation might result in undesirable vibrations and thus human discomfort. It must be emphasized that the total structural mass corresponds to $372.83 \mathrm{t}$.

In sequence, Figs. 9-12 present some chosen vibration modes of the floor, which might be excited by the dynamic load positioning (Fig. 13). It must be emphasized that all steel-concrete composite floor vibration modes present a predominant flexural behaviour.

The force frequency range corresponding to the third harmonic of aerobics activities $(\mathrm{Hz})$ for the dynamic loading Model I [3] and the dynamic loading Model II

Table 1 Natural frequencies and modal masses.

\begin{tabular}{lll}
\hline $\begin{array}{l}\text { Vibration } \\
\text { modes }\end{array}$ & $\begin{array}{l}\text { Composite floor } \\
\text { frequencies }(\mathrm{Hz})\end{array}$ & $\begin{array}{l}\text { Modal mass/total structural } \\
\text { mass ratio }(\%)\end{array}$ \\
\hline$f_{01}$ & 6.29 & 11.55 \\
$f_{02}$ & 6.52 & 13.03 \\
$f_{03}$ & 6.53 & 20.60 \\
$f_{04}$ & 6.60 & 13.98 \\
$f_{05}$ & 6.98 & 18.08 \\
$f_{06}$ & 7.10 & 12.20 \\
$f_{07}$ & 7.27 & 19.51 \\
$f_{08}$ & 7.29 & 17.32 \\
$f_{09}$ & 7.33 & 16.25 \\
$f_{10}$ & 7.34 & 19.53 \\
$f_{11}$ & 7.52 & 32.42 \\
$f_{12}$ & 7.59 & 20.51 \\
$f_{13}$ & 9.30 & 16.81 \\
$f_{14}$ & 9.48 & 24.02 \\
$f_{15}$ & 9.54 & 25.41 \\
$f_{16}$ & 10.04 & 35.61 \\
$f_{17}$ & 10.44 & 19.27 \\
$f_{18}$ & 10.60 & 29.33 \\
$f_{19}$ & 10.71 & 30.77 \\
$f_{20}$ & 10.86 & 50.06 \\
\hline
\end{tabular}

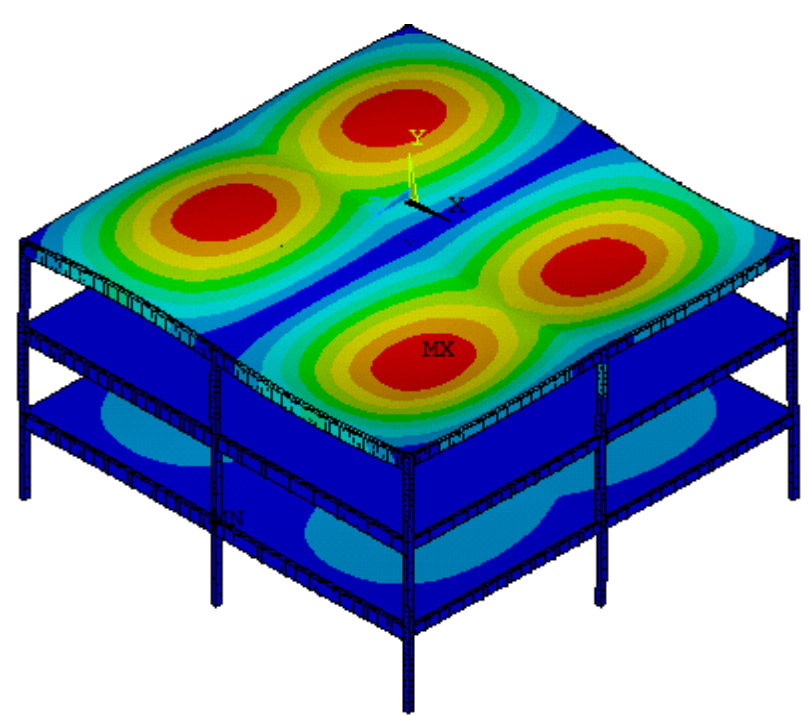

Fig. 9 1st vibration mode $\left(f_{01}=6.29 \mathrm{~Hz}\right)$. 


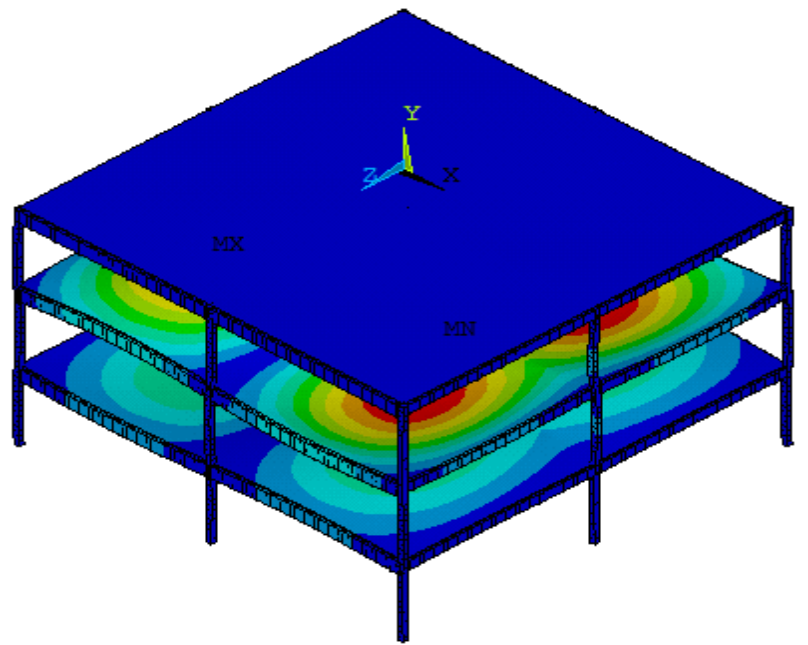

Fig. 10 2nd vibration mode $\left(f_{02}=6.52 \mathrm{~Hz}\right)$.

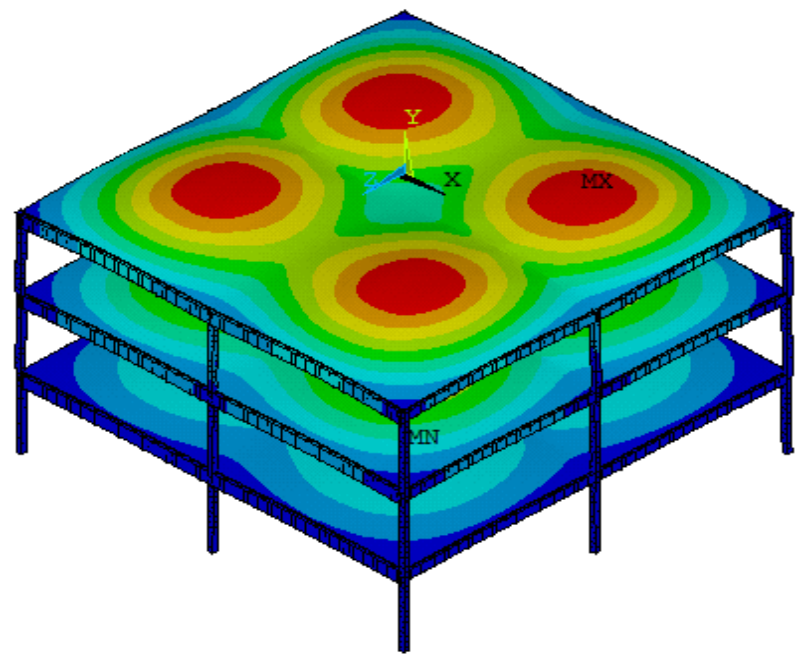

Fig. 113 rd vibration mode $\left(f_{03}=6.53 \mathrm{~Hz}\right)$.

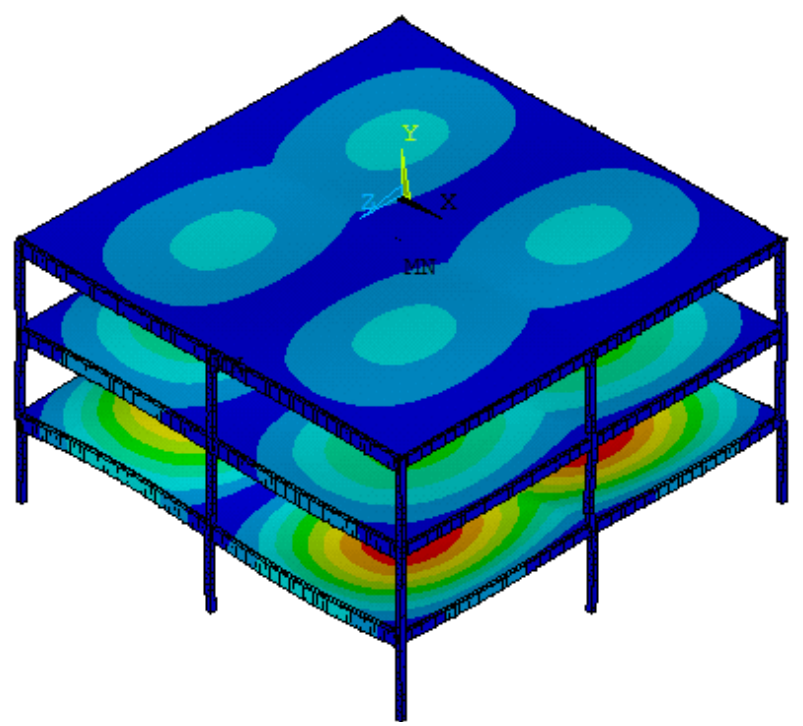

Fig. 12 4th vibration mode $\left(f_{04}=6.60 \mathrm{~Hz}\right)$.
[7] vary from $5.66 \mathrm{~Hz}$ to $8.57 \mathrm{~Hz}$ and from $4.5 \mathrm{~Hz}$ to 8.4 $\mathrm{Hz}$, respectively.

It can be noted that the modal analysis may predict some unwanted vibration possibilities. In this sense, the fundamental composite floor frequency should be at least equal to $9.2 \mathrm{~Hz}$ [1-5] for aerobics considering the structural system as a light floor or $8.4 \mathrm{~Hz}$ for rhythmic activities according to Smith, Hicks and Devine [7].

\section{Human Comfort Assessment}

The dynamic loading was uniformly distributed over the half area of the steel-concrete composite building second floor, representing 50 people practicing aerobics $\left(0.25\right.$ people $\left./ \mathrm{m}^{2}\right)$ [5], as illustrated in Fig. 13. This way, simulation of these rhythmic human actions was represented by the dynamic loading Models I and II, developed respectively by Faisca [3], Ellis and Ji [6], and Smith, Hicks and Devine [7].

It is also assumed that a single person's weight is equal to $800 \mathrm{~N}[1,2]$. In this study, the structural damping is taken as $\xi=1 \%$ ( $\xi=0.01)$ according to ISO10137 [9]. The dynamic response of the investigated building was obtained from the central nodes (Sections A to G), of each floor bay regarding the three levels of the building, as shown in Fig. 14.

The steel-concrete composite floor accelerations were evaluated on the steady state response on the

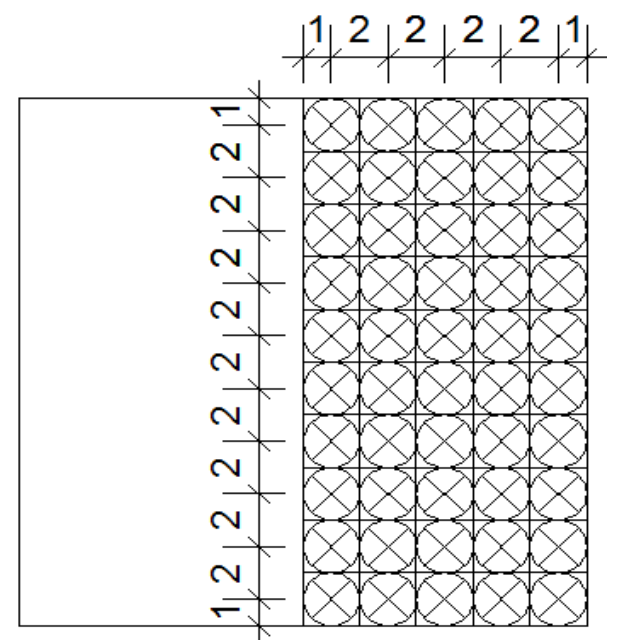

Fig. 13 Aerobics on the second floor (units in $\mathbf{m}$ ). 


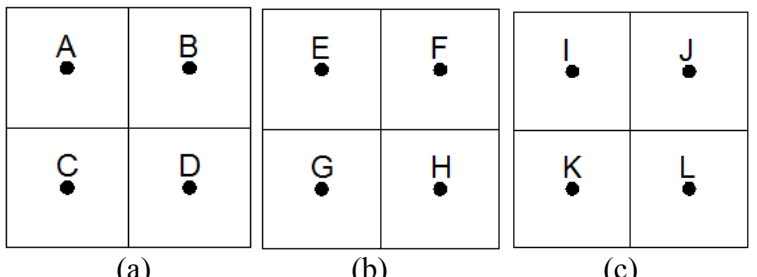

Fig. 14 Investigated sections of the building floors: (a) first floor; (b) second floor; (c) third floor.

structural model, based on the values of the peak unweighted accelerations (steady-state response) $a_{p}$, RMS weighted accelerations $a_{w, r m s}$ and also the vibration dose values $V D V$.

In sequence, Table 2 shows the unweighted accelerations, RMS weighted accelerations and the VDV acceptance criteria, respectively. An extensive parametric study was carried out so that the third harmonic of the excitation frequencies (aerobics) matches each natural floor frequency as much as possible to induce resonance. Then, 12 load cases were performed for both the dynamic loading Models I and II, totalling 24 studied cases. Table 3 shows the parameters adopted for the dynamic loading Model I
$\left(C D=0.93\right.$ and $\left.K_{p}=2.78[3]\right)$, in order to represent the aerobics class (Eq. (1)). Regarding the dynamic loading Model II parameters, the following ones were used: $v=50$ persons, phase lag $\phi_{n}$, for the first three harmonics equal to $\pi / 6,-\pi / 6$ and $\pi / 2[6,7]$, respectively (Eqs. (2) to (5)).

Tables 4 to 9 show the composite multi-storey building dynamic response for the dynamic loading Models I and II, respectively. It must be noted that the bold values shown in these tables represent the exceeding values according to the human comfort criteria (Table 2).

Based on the dynamic response obtained applying the loading Models I and II to simulate the aerobics class performed by 50 people on the second floor, it was observed that the highest values (peak and RMS weighted accelerations and $V D V$ values), were related to the second and third vibration modes $\left(f_{02}=6.52 \mathrm{~Hz}\right.$ and $f_{03}=6.53 \mathrm{~Hz}$ ), mainly on the second floor area where the dynamic loads were applied (Sections F and H) for both dynamic loading models (Tables 4-9).

Table 2 Human comfort acceptance criteria.

\begin{tabular}{lllll}
\hline Murray, Allen and Ungar [5] & Smith, Hicks and Devine [7] & Ellis and Littler [10] & Setareh [11] & Person's reaction \\
\hline $\mathrm{a}_{\mathrm{p}}\left(\mathrm{m} / \mathrm{s}^{2}\right)$ & $\mathrm{a}_{\mathrm{w}, \mathrm{rms}}\left(\mathrm{m} / \mathrm{s}^{2}\right)$ & VDV $\left(\mathrm{m} / \mathrm{s}^{1.75}\right)$ & VDV $(\mathrm{m} / \mathrm{s} 1.75)$ & \\
\hline & $<0.35$ & $<0.66$ & $<0.50$ & Reasonable \\
0.5 & $0.35 \sim 1.27$ & $0.66 \sim 2.38$ & $0.50 \sim 3.50$ & Disturbing \\
& $1.27 \sim 2.47$ & $2.38 \sim 4.64$ & $3.50 \sim 6.90$ & Unacceptable \\
& $>2.47$ & $>4.64$ & $>6.90$ & Panic \\
\hline
\end{tabular}

Table 3 Parameters used in dynamic loading model I.

\begin{tabular}{lllllll}
\hline Cases & $T_{c}(\mathrm{~s})$ & $T_{s}(\mathrm{~s})$ & $T(\mathrm{~s})$ & $\mathrm{f}_{01}(\mathrm{~Hz})$ & $f_{02}(\mathrm{~Hz})$ & $f_{03}(\mathrm{~Hz})$ \\
\hline$f_{01}$ & 0.34 & 0.138 & 0.478 & 2.09 & 4.18 & 6.28 \\
$f_{02}$ & 0.34 & 0.120 & 0.460 & 2.17 & 4.35 & 6.52 \\
$f_{03}$ & 0.34 & 0.119 & 0.459 & 2.18 & 4.36 & 6.54 \\
$f_{04}$ & 0.34 & 0.115 & 0.455 & 2.20 & 4.40 & 6.59 \\
$f_{05}$ & 0.34 & 0.090 & 0.430 & 2.33 & 4.65 & 6.98 \\
$f_{06}$ & 0.34 & 0.082 & 0.422 & 2.37 & 4.74 & 7.11 \\
$f_{07}$ & 0.34 & 0.072 & 0.412 & 2.43 & 4.85 & 7.28 \\
$f_{08}$ & 0.34 & 0.071 & 0.411 & 2.43 & 4.87 & 7.30 \\
$f_{09}$ & 0.34 & 0.069 & 0.409 & 2.44 & 4.89 & 7.33 \\
$f_{10}$ & 0.34 & 0.069 & 0.409 & 2.44 & 4.89 & 7.33 \\
$f_{11}$ & 0.34 & 0.059 & 0.399 & 2.51 & 5.01 & 7.52 \\
$f_{12}$ & 0.34 & 0.055 & 0.395 & 2.53 & 5.06 & 7.59
\end{tabular}


Table 4 Loading Model I: peak accelerations $\left(\mathrm{m} / \mathrm{s}^{2}\right)$.

\begin{tabular}{|c|c|c|c|c|c|c|}
\hline \multirow{3}{*}{ Cases } & \multicolumn{6}{|c|}{$a_{p}\left(\mathrm{~m} / \mathrm{s}^{2}\right)$} \\
\hline & \multicolumn{2}{|c|}{ First floor } & \multicolumn{2}{|c|}{ Second floor } & \multicolumn{2}{|c|}{ Third floor } \\
\hline & $\mathrm{A} / \mathrm{C}$ & $\mathrm{B} / \mathrm{D}$ & $\mathrm{E} / \mathrm{G}$ & $\mathrm{F} / \mathrm{H}$ & $\mathrm{I} / \mathrm{K}$ & $\mathrm{J} / \mathrm{L}$ \\
\hline$\overline{f_{01}}$ & 0.12 & 0.06 & 0.29 & 0.66 & 0.15 & 0.16 \\
\hline$f_{02}$ & 0.50 & 0.26 & 0.71 & 1.56 & 0.46 & 0.49 \\
\hline$f_{03}$ & 0.52 & 0.31 & 0.70 & 1.58 & 0.48 & 0.51 \\
\hline$f_{04}$ & 0.41 & 0.38 & 0.65 & 1.44 & 0.46 & 0.42 \\
\hline$f_{05}$ & 0.10 & 0.12 & 0.44 & 0.70 & 0.30 & 0.29 \\
\hline$f_{06}$ & 0.11 & 0.13 & 0.46 & 0.69 & 0.31 & 0.29 \\
\hline$f_{07}$ & 0.13 & 0.13 & 0.49 & 0.69 & 0.34 & 0.34 \\
\hline$f_{08}$ & 0.13 & 0.13 & 0.51 & 0.68 & 0.35 & 0.35 \\
\hline$f_{09}$ & 0.14 & 0.13 & 0.55 & 0.68 & 0.37 & 0.37 \\
\hline$f_{10}$ & 0.14 & 0.13 & 0.55 & 0.68 & 0.37 & 0.37 \\
\hline$f_{11}$ & 0.34 & 0.34 & 0.80 & 1.01 & 0.55 & 0.55 \\
\hline$f_{12}$ & 0.42 & 0.41 & 0.72 & 1.14 & 0.41 & 0.42 \\
\hline
\end{tabular}

Table 5 Loading Model I: RMS accelerations $\left(\mathrm{m} / \mathrm{s}^{2}\right)$.

\begin{tabular}{|c|c|c|c|c|c|c|}
\hline \multirow{3}{*}{ Cases } & \multicolumn{6}{|c|}{$a_{w, r m s}\left(\mathrm{~m} / \mathrm{s}^{2}\right)$} \\
\hline & \multicolumn{2}{|c|}{ First floor } & \multicolumn{2}{|c|}{ Second floor } & \multicolumn{2}{|c|}{ Third floor } \\
\hline & $\mathrm{A} / \mathrm{C}$ & $\mathrm{B} / \mathrm{D}$ & $\mathrm{E} / \mathrm{G}$ & $\mathrm{F} / \mathrm{H}$ & $\mathrm{I} / \mathrm{K}$ & $\mathrm{J} / \mathrm{L}$ \\
\hline$f_{01}$ & 0.05 & 0.02 & 0.11 & 0.30 & 0.06 & 0.07 \\
\hline$f_{02}$ & 0.29 & 0.17 & 0.45 & 0.90 & 0.30 & 0.30 \\
\hline$f_{03}$ & 0.30 & 0.19 & 0.46 & 0.90 & 0.31 & 0.31 \\
\hline$f_{04}$ & 0.25 & 0.23 & 0.44 & 0.79 & 0.30 & 0.27 \\
\hline$f_{05}$ & 0.04 & 0.06 & 0.23 & 0.26 & 0.14 & 0.13 \\
\hline$f_{06}$ & 0.04 & 0.06 & 0.23 & 0.22 & 0.15 & 0.14 \\
\hline$f_{07}$ & 0.05 & 0.05 & 0.29 & 0.23 & 0.19 & 0.18 \\
\hline$f_{08}$ & 0.05 & 0.06 & 0.30 & 0.24 & 0.19 & 0.19 \\
\hline$f_{09}$ & 0.05 & 0.06 & 0.33 & 0.26 & 0.21 & 0.21 \\
\hline$f_{10}$ & 0.05 & 0.06 & 0.33 & 0.26 & 0.21 & 0.21 \\
\hline$f_{11}$ & 0.21 & 0.21 & 0.54 & 0.55 & 0.35 & 0.35 \\
\hline$f_{12}$ & 0.25 & 0.25 & 0.49 & 0.58 & 0.28 & 0.28 \\
\hline
\end{tabular}

Table 6 Loading Model I: $V D V$ values $\left(\mathrm{m} / \mathrm{s}^{1.75}\right)$.

\begin{tabular}{lllllll}
\hline \multirow{2}{*}{ Cases } & \multicolumn{3}{c}{$V D V\left(\mathrm{~m} / \mathrm{s}^{1.75}\right)$} \\
\cline { 2 - 7 } & $\mathrm{A} / \mathrm{C}$ & $\mathrm{B} / \mathrm{D}$ & $\mathrm{E} / \mathrm{G}$ & $\mathrm{F} / \mathrm{H}$ & $\mathrm{I} / \mathrm{K}$ & \multicolumn{2}{c}{ Third floor } \\
\hline$n_{01}$ & 0.11 & 0.05 & 0.24 & $\mathbf{0 . 6 6}$ & 0.14 & 0.15 \\
$f_{02}$ & $\mathbf{0 . 6 2}$ & 0.36 & $\mathbf{0 . 9 3}$ & $\mathbf{1 . 8 7}$ & $\mathbf{0 . 6 1}$ & $\mathbf{0 . 6 3}$ \\
$f_{03}$ & $\mathbf{0 . 6 3}$ & 0.40 & $\mathbf{0 . 9 5}$ & $\mathbf{1 . 8 9}$ & $\mathbf{0 . 6 4}$ & $\mathbf{0 . 6 4}$ \\
$f_{04}$ & $\mathbf{0 . 5 2}$ & 0.50 & $\mathbf{0 . 8 9}$ & $\mathbf{1 . 6 5}$ & $\mathbf{0 . 6 2}$ & $\mathbf{0 . 5 6}$ \\
$f_{05}$ & 0.09 & 0.13 & $\mathbf{0 . 4 7}$ & $\mathbf{0 . 5 9}$ & 0.29 & 0.27 \\
$f_{06}$ & 0.09 & 0.12 & $\mathbf{0 . 4 8}$ & $\mathbf{0 . 5 1}$ & 0.30 & 0.28 \\
$f_{07}$ & 0.11 & 0.12 & $\mathbf{0 . 5 8}$ & $\mathbf{0 . 5 0}$ & 0.38 & 0.37 \\
$f_{08}$ & 0.11 & 0.12 & $\mathbf{0 . 6 0}$ & $\mathbf{0 . 5 2}$ & 0.39 & 0.38 \\
$f_{09}$ & 0.12 & 0.13 & $\mathbf{0 . 6 6}$ & $\mathbf{0 . 5 6}$ & 0.43 & 0.42 \\
$f_{10}$ & 0.12 & 0.13 & $\mathbf{0 . 6 6}$ & $\mathbf{0 . 5 6}$ & 0.43 & 0.42 \\
$f_{11}$ & 0.44 & 0.44 & $\mathbf{1 . 1 0}$ & $\mathbf{1 . 1 7}$ & $\mathbf{0 . 6 3}$ & $\mathbf{0 . 6 3}$ \\
$f_{12}$ & $\mathbf{0 . 5 3}$ & $\mathbf{0 . 5 3}$ & $\mathbf{0 . 9 9}$ & $\mathbf{1 . 2 3}$ & $\mathbf{0 . 5 6}$ & $\mathbf{0 . 5 6}$ \\
\hline
\end{tabular}


Table 7 Loading Model II: peak accelerations $\left(\mathrm{m} / \mathrm{s}^{2}\right)$.

\begin{tabular}{|c|c|c|c|c|c|c|}
\hline \multirow{3}{*}{ Cases } & \multicolumn{6}{|c|}{$a_{p}\left(\mathrm{~m} / \mathrm{s}^{2}\right)$} \\
\hline & \multicolumn{2}{|c|}{ First floor } & \multicolumn{2}{|c|}{ Second floor } & \multicolumn{2}{|c|}{ Third floor } \\
\hline & $\mathrm{A} / \mathrm{C}$ & $\mathrm{B} / \mathrm{D}$ & $\mathrm{E} / \mathrm{G}$ & $\mathrm{F} / \mathrm{H}$ & $\mathrm{I} / \mathrm{K}$ & $\mathrm{J} / \mathrm{L}$ \\
\hline$f_{01}$ & 0.34 & 0.21 & 1.00 & 1.91 & 0.49 & 0.50 \\
\hline$f_{02}$ & 1.43 & 0.77 & 2.04 & 4.20 & 1.34 & 1.41 \\
\hline$f_{03}$ & 1.47 & 0.86 & 2.03 & 4.15 & 1.36 & 1.43 \\
\hline$f_{04}$ & 1.10 & 1.06 & 1.86 & 3.31 & 1.24 & 1.15 \\
\hline$f_{05}$ & 0.34 & 0.44 & 1.39 & 2.10 & 0.80 & 0.78 \\
\hline$f_{06}$ & 0.38 & 0.34 & 1.48 & 2.13 & 0.87 & 0.84 \\
\hline$f_{07}$ & 0.36 & 0.38 & 1.55 & 2.19 & 0.93 & 0.88 \\
\hline$f_{08}$ & 0.37 & 0.38 & 1.55 & 2.19 & 0.94 & 0.88 \\
\hline$f_{09}$ & 0.43 & 0.39 & 1.55 & 2.20 & 0.98 & 0.89 \\
\hline$f_{10}$ & 0.43 & 0.39 & 1.55 & 2.21 & 0.99 & 0.90 \\
\hline$f_{11}$ & 0.95 & 0.94 & 2.19 & 2.53 & 1.42 & 1.43 \\
\hline$f_{12}$ & 1.18 & 1.17 & 2.10 & 2.61 & 1.25 & 1.28 \\
\hline
\end{tabular}

Table 8 Loading Model II: RMS accelerations $\left(\mathrm{m} / \mathrm{s}^{2}\right)$.

\begin{tabular}{|c|c|c|c|c|c|c|}
\hline \multirow{3}{*}{ Cases } & \multicolumn{6}{|c|}{$a_{w, r m s}\left(\mathrm{~m} / \mathrm{s}^{2}\right)$} \\
\hline & \multicolumn{2}{|c|}{ First floor } & \multicolumn{2}{|c|}{ Second floor } & \multicolumn{2}{|c|}{ Third floor } \\
\hline & $\mathrm{A} / \mathrm{C}$ & $\mathrm{B} / \mathrm{D}$ & $\mathrm{E} / \mathrm{G}$ & $\mathrm{F} / \mathrm{H}$ & $\mathrm{I} / \mathrm{K}$ & $\mathrm{J} / \mathrm{L}$ \\
\hline$f_{01}$ & 0.16 & 0.06 & 0.39 & 0.93 & 0.22 & 0.25 \\
\hline$f_{02}$ & 0.87 & 0.48 & 1.37 & 2.67 & 0.89 & 0.90 \\
\hline$f_{03}$ & 0.88 & 0.52 & 1.38 & 2.68 & 0.92 & 0.92 \\
\hline$f_{04}$ & 0.72 & 0.66 & 1.26 & 2.22 & 0.87 & 0.78 \\
\hline$f_{05}$ & 0.15 & 0.21 & 0.59 & 0.60 & 0.37 & 0.35 \\
\hline$f_{06}$ & 0.15 & 0.16 & 0.59 & 0.50 & 0.37 & 0.35 \\
\hline$f_{07}$ & 0.15 & 0.15 & 0.72 & 0.50 & 0.46 & 0.45 \\
\hline$f_{08}$ & 0.15 & 0.15 & 0.74 & 0.52 & 0.48 & 0.47 \\
\hline$f_{09}$ & 0.15 & 0.15 & 0.82 & 0.59 & 0.54 & 0.53 \\
\hline$f_{10}$ & 0.16 & 0.16 & 0.83 & 0.60 & 0.55 & 0.53 \\
\hline$f_{11}$ & 0.59 & 0.60 & 1.49 & 1.48 & 0.97 & 0.97 \\
\hline$f_{12}$ & 0.73 & 0.73 & 1.44 & 1.64 & 0.83 & 0.83 \\
\hline
\end{tabular}

Table 9 Loading Model II: VDV values $\left(\mathrm{m} / \mathrm{s}^{1.75}\right)$.

\begin{tabular}{|c|c|c|c|c|c|c|}
\hline \multirow{3}{*}{ Cases } & \multicolumn{6}{|c|}{$V D V\left(\mathrm{~m} / \mathrm{s}^{1.75}\right)$} \\
\hline & \multicolumn{2}{|c|}{ First floor } & \multicolumn{2}{|c|}{ Second floor } & \multicolumn{2}{|c|}{ Third floor } \\
\hline & $\mathrm{A} / \mathrm{C}$ & $\mathrm{B} / \mathrm{D}$ & $\mathrm{E} / \mathrm{G}$ & $\mathrm{F} / \mathrm{H}$ & $\mathrm{I} / \mathrm{K}$ & $\mathrm{J} / \mathrm{L}$ \\
\hline$\overline{f_{01}}$ & 0.34 & 0.15 & 0.82 & 1.89 & 0.47 & 0.49 \\
\hline$f_{02}$ & 1.84 & 1.01 & 2.79 & 5.47 & 1.83 & 1.86 \\
\hline$f_{03}$ & 1.88 & 1.10 & 2.83 & 5.52 & 1.89 & 1.92 \\
\hline$f_{04}$ & 1.48 & 1.39 & 2.54 & 4.48 & 1.76 & 1.59 \\
\hline$f_{05}$ & 0.35 & 0.26 & 1.24 & 1.45 & 0.78 & 0.72 \\
\hline$f_{06}$ & 0.34 & 0.34 & 1.27 & 1.23 & 0.80 & 0.75 \\
\hline$f_{07}$ & 0.34 & 0.34 & 1.47 & 1.25 & 0.95 & 0.91 \\
\hline$f_{08}$ & 0.34 & 0.34 & 1.52 & 1.27 & 0.98 & 0.95 \\
\hline$f_{09}$ & 0.36 & 0.35 & 1.66 & 1.39 & 1.09 & 1.06 \\
\hline$f_{10}$ & 0.36 & 0.35 & 1.68 & 1.40 & 1.10 & 1.07 \\
\hline$f_{11}$ & 1.24 & 1.25 & 3.03 & 3.06 & 1.97 & 1.96 \\
\hline $\mathrm{f}_{12}$ & 1.54 & 1.54 & 2.90 & 3.41 & 1.67 & 1.67 \\
\hline
\end{tabular}


The results reported by the loading Model I (Tables 4-6) pointed out that the sections of the second floor (E, $\mathrm{F}, \mathrm{G}$ and $\mathrm{H}$ ) presented the highest acceleration values in comparison to the nodes of the first and third floor (A, $\mathrm{B}, \mathrm{C}, \mathrm{D}$ and $\mathrm{I}, \mathrm{J}, \mathrm{K}, \mathrm{L}$, respectively), exceeding the recommended human comfort limits and thus causing undesirable vibrations in the structure (Table 2). However, it can be noted that according to the VDV assessment (Table 6), the human comfort limit (Table 2) was classified as disturbing for the second and third floor considering the investigated load cases $\mathrm{f}_{02}, f_{03}, f_{04}$, $f_{11}$ and $f_{12}$ (Tables 2 and 6).

Regarding the loading Model II (Tables 7-9), it was verified that only the load cases $f_{01}$ (Nodes A, B, C, D, I, $\mathrm{J}, \mathrm{K}, \mathrm{L}$ ) and $\mathrm{f}_{05}$ to $f_{10}$ (Nodes $\mathrm{A}, \mathrm{B}, \mathrm{C}$ and $\mathrm{D}$ ) indicated acceptable human comfort levels to the practice of aerobic activities, respecting the recommended limits of peak accelerations, $R M S$ and $V D V$ values. On the other hand, most of cases investigated in this analysis have shown uncomfortable and disturbing vibrations (Table 2) for the second and third floors, especially the load cases $f_{02}$ and $f_{03}$ for the areas of the second floor where the human rhythmic activity was taken place (Sections $\mathrm{F}$ and $\mathrm{H}$ ), which presented unacceptable vibration levels.

Therefore, it must be emphasized that the vibration transmissibility to the first and third floors gets higher for most of the building natural frequencies varying from $6.29 \mathrm{~Hz}$ to $7.59 \mathrm{~Hz}$, as presented in Tables 4-9. This way, people standing on these floors could fell even more a greater discomfort once they act as passive persons practising others activities.

In order to illustrate all these quantitative analysis, Figs. 15 and 16 show the building composite floor dynamic response on the second floor (Sections F and $\mathrm{H}$ in Figs. 13 and 14), in time and frequency domain, considering the excitation frequency tuned to the third vibration mode ( $f_{03}=6.54 \mathrm{~Hz}$ ), evaluated as one of the worst design case scenario.

Based on the results presented in Figs. 15 and 16 and Tables 4-9, it can be concluded that the dynamic loading Model II [7] induced higher vibration levels than the dynamic loading Model I [3]. It means that the Fourier coefficients of the SCI function [7], especially the third Fourier coefficient (Figs. 15 and 16), are more energetics than the Faisca function ones. On the other hand, through a comparison among the two investigated force functions, the Faisca [3] dynamic model seems to offer larger design parameters variations.

Considering all obtained results along the investigation, the Faisca [3] function might be considered for an economical design. It is important to emphasize that the impact coefficient, $K_{p}$, and the phase coefficient variation, $C D$, for human rhythmic activities used in Faisca [3] dynamic loading model

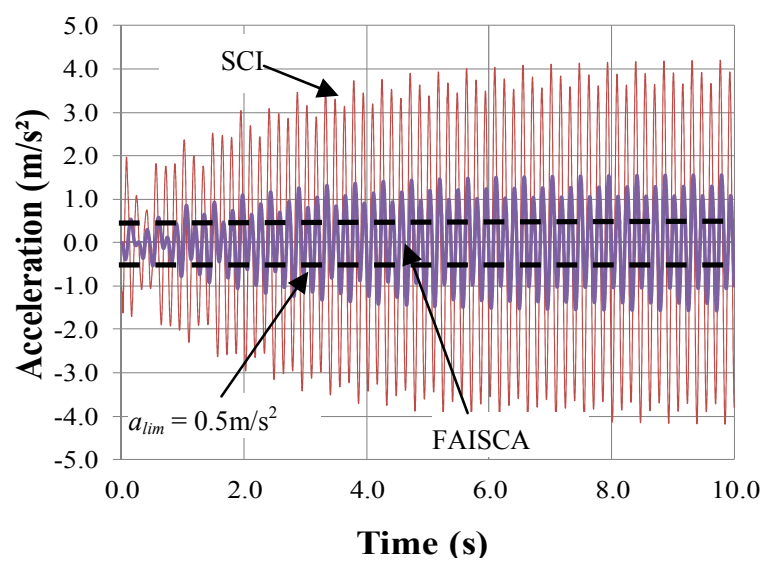

Fig. 15 Dynamic structural response of Sections $F$ and $H$ (2nd floor) in time domain $\left(f_{02}=6.52 \mathrm{~Hz}\right)$.

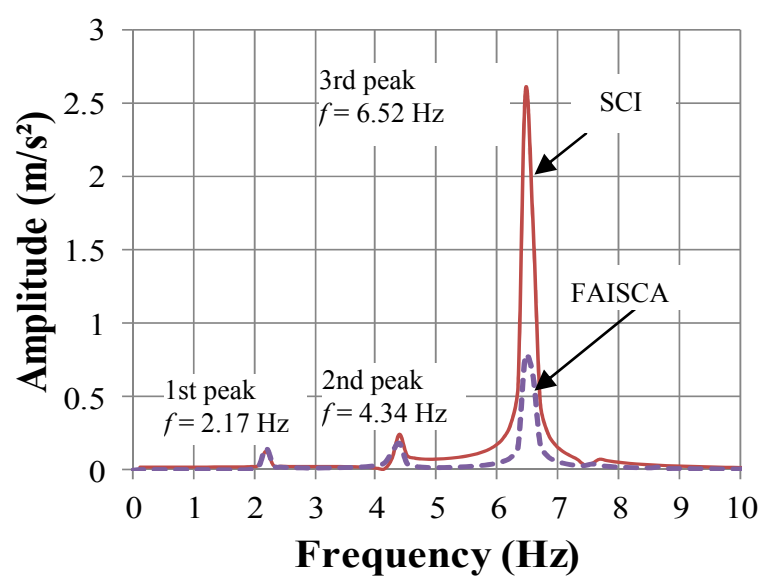

Fig. 16 Dynamic structural response of Sections $F$ and $H$ (2nd floor) in frequency domain $\left(f_{02}=6.52 \mathrm{~Hz}\right.$ ). 
were obtained based on a long series of experimental tests and probabilistic analyses. Important variations which lead to the reduction of the human dynamic actions on the structure, such as phase lags between the individuals and change of rhythm during the activity are already embedded in these coefficients.

\section{Conclusions}

This paper investigated the dynamic behaviour of a multi-storey building composed by three composite floors spanning $20 \mathrm{~m}$ by $20 \mathrm{~m}$, when subjected to the dynamic actions coming from human rhythmic activities (aerobics) and performed by fifty people. The investigated building was numerically modelled based on the use of the ANSYS program [8]. This computational model enabled a complete dynamic evaluation of the investigated system in terms of human comfort and its associated vibration serviceability limit states.

It was found that the natural frequencies of the studied structural model are in the range of $6.29 \mathrm{~Hz}$ to $7.59 \mathrm{~Hz}$, corresponding to the same frequency range of the third harmonic of the dynamic excitation induced by aerobic activities [1-5]. Consequently, the building floors may resonate with the third harmonic of the human rhythmic activities practiced on the structure so that excessive vibrations levels from the human comfort point of view can occur.

The dynamic structural response indicated that the worst loading cases are related to the area where the human rhythmic activity (aerobics) was taken place, when the excitation frequency was tuned to the second and third vibration modes of the building floor system. The maximum values of the dynamic response were equal to $1.58 \mathrm{~m} / \mathrm{s}^{2} ; 0.90 \mathrm{~m} / \mathrm{s}^{2}$ and $1.89 \mathrm{~m} / \mathrm{s}^{1.75}$ (peak acceleration, RMS and VDV, respectively), when the dynamic loading Model I was considered. On the other hand, these maximum values were equal to $4.20 \mathrm{~m} / \mathrm{s}^{2}$; $2.68 \mathrm{~m} / \mathrm{s}^{2}$ and $5.52 \mathrm{~m} / \mathrm{s}^{1.75}$ (peak acceleration, $R M S$ and $V D V$, respectively), related to the use of the dynamic loading Model II. These values indicated uncomfortable and unacceptable vibrations levels to the people who practise aerobics according to several author and design recommendations [5, 7, 10, 11].

It must be emphasized that the results indicated that in most of analysed situations, the vibration transmissibility to the upper and lower floor of the composite building indicated disturbing vibration levels to the persons who are not directly involved to the human rhythmic activity. Therefore, the dynamic analysis showed that the floor fundamental frequency should be moved away from the force activity range or a vibration control system must be installed on the structural system of the building, in order to guarantee the human comfort of the occupants.

\section{Acknowledgments}

The authors gratefully acknowledge the financial support for this work provided by the Brazilian Science Foundation's CAPES, CNPq and FAPERJ.

\section{References}

[1] Campista, F. F. 2015. "Vibration Analysis and Human Comfort Evaluation of Steel-Concrete Composite Floors when Subjected to Rhythmic Human Actions." M.Sc. dissertation, State University of Rio de Janeiro, UERJ. (in Portuguese)

[2] Gaspar, C. M. R. 2013. "Dynamic Analysis and Vibration Control of Buildings' Floors When Submitted to Human Rhythmic Activities.” M.Sc. dissertation, State University of Rio de Janeiro, UERJ. (in Portuguese)

[3] Faisca, R. G. 2003. "Characterization of Dynamic Loads due to Human Activities." Ph.D. thesis, Civil Engineering Department, COPPE/UFRJ. (in Portuguese)

[4] Bachmann, H., Ammann, W. J., Deischl, F., Eisenmann, J., Floegl, J., Hirsch, G. H., et al. 1995. Vibration Problems in Structures-Practical Guidelines. Basel (Switzerland): Institut für Baustatik und Konstruktion, Birkhäuser.

[5] Murray, T. M., Allen, D. E., and Ungar, E. E. 2003 "Floor Vibrations due to Human Activity." In Steel Design Guide Series. Chicago: American Institute of Steel Construction.

[6] Ellis, B. R., and Ji, T. 2004., "Response of Structures Subject to Dynamic Crowd Loads." BRE Digest 426.

[7] Smith, A. L., Hicks, S. J., and Devine, P. J. 2009. Design of Floors for Vibrations: A New Approach. Silwood Park, Ascot, UK: SCI Publication.

[8] ANSYS Swanson Analysis Systems, Inc. 2007. Products 
ANSYS Academic Research, Using FLEXIm v10.8.0.7 build 26147. ANSYS Swanson Analysis Systems, Inc.

[9] International Standard Organization. 2007. Bases for Design of Structures-Serviceability of Buildings and Walkways against Vibrations. ISO 10137.

[10] Ellis, B. R., and Littler, J. D. 2004. "Response of Cantilever Grandstands to Crowd Loads. Part I:
Serviceability Evaluation." In Proceedings of the Institution of Civil Engineers - Structures and Buildings 157 (SB4): 235-41.

[11] Setareh, M. 2012. "Evaluation and Assessment of Vibrations Owing to Human Activity." In Proceedings of the Institution of Civil Engineers-Structures and Buildings 165 (SB5): 219-31. 